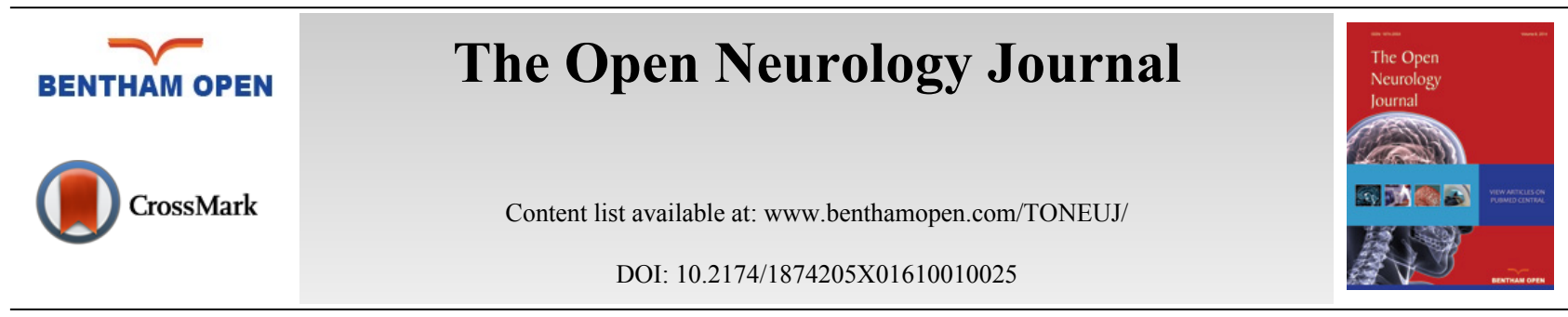

RESEARCH ARTICLE

\title{
No Association Between rs7077361 in ITGA8 and Parkinson's Disease in Sweden
}

\author{
Caroline Ran ${ }^{1, *}$, Rawand Naiel Mehdi ${ }^{1}$, Camilla Fardell ${ }^{2}$, Fengqing Xiang ${ }^{3}$, Hans Nissbrandt ${ }^{2}$, Olof \\ Sydow $^{4}$, Karin Wirdefeldt ${ }^{5,6}$ and Andrea Carmine Belin ${ }^{1}$ \\ ${ }^{I}$ Department of Neuroscience, Karolinska Institutet, Stockholm, Sweden \\ ${ }^{2}$ Department of Pharmacology, Sahlgrenska Academy at the University of Gothenburg, Gothenburg, Sweden \\ ${ }^{3}$ Department of Women's and Children's Health, Karolinska Institutet, Stockholm, Sweden \\ ${ }^{4}$ Department of Neurology, Karolinska University Hospital Solna, Stockholm, Sweden \\ ${ }^{5}$ Department of Medical Epidemiology and Biostatistics, Karolinska Institutet, Stockholm, Sweden \\ ${ }^{6}$ Department of Clinical Neuroscience, Karolinska Institutet, Stockholm, Sweden
}

Received: March 13, 2016

Revised: May 10, 2016

Accepted: May 15, 2016

\section{Abstract:}

\section{Background:}

Integrin alpha 8 (ITGA8) encodes the alpha 8 subunit of the integrin alpha8beta1 protein and has recently been suggested as a new candidate gene for Parkinson's disease, an age related neurodegenerative disease with unknown etiology. ITGA8 is a transmembrane protein involved in several cellular processes, such as cell adhesion, migration and cytoskeletal rearrangement.

\section{Objective:}

Screen a Swedish case control material for rs7077361, a genetic variant in ITGA8, in order to investigate its possible implication in Parkinson's disease in Sweden.

\section{Method:}

Rs7077361 was genotyped using TaqMan quantitative Real-time PCR and tested for association using appropriate statistical methods.

Results:

We have screened 502 Swedish Parkinson patients and 599 healthy control individuals for rs7077361 in ITGA8. This genetic variant was in Hardy Weinberg equilibrium in the Swedish population. Allele and genotype frequencies were highly similar between the patients and controls and statistical testing showed that this genetic maker did not associate with Parkinson's disease $(p=0.67)$.

\section{Conclusion:}

Our results do not support the hypothesis of ITGA8 as a candidate gene for Parkinson's disease in Sweden.

Keywords: Association study, ITGA8, LRRK2, Parkinson's disease, rs7077361, SNP.

\section{INTRODUCTION}

Integrin alpha 8 (ITGA8) is a large gene consisting of 30 exons which is located on chromosome 10p13. It encodes

\footnotetext{
* Address correspondence to this author at the Department of Neuroscience, Karolinska Institutet, Retzius väg 8, B2:4, 17177 Stockholm, Sweden; Tel: +46-8-524 86648; E-mail: caroline.ran@ki.se
} 
the alpha 8 subunit of the integrin alpha8betal protein [1, 2]. This transmembrane protein binds to the extracellularmatrix and surrounding ligands and is involved in the mediation of many cellular processes, such as cell adhesion, migration and cytoskeletal rearrangement [3 - 5]. In a large meta-analysis by Lill et al., including data from 828 association studies and several genome wide association studies (GWAS), ITGA8 was proposed as a candidate gene for Parkinson's disease (PD) [6]. Further, a trend of an increase in non-synonymous-coding variants in ITGA8 was recently discovered in individuals with $\mathrm{PD}$ in the East Asian population [7]. Parkinson's disease is an age-related complex genetic disorder characterized by the progressive loss of neurons, in particular the dopaminergic neurons in substantia nigra pars compacta, which is accompanied by motor symptoms such as tremor, bradykinesia and rigidity [8, 9]. $10 \%$ of the patients suffer from rare monogenetic forms of the disease. For the large majority of the PD patients however there is no known cause, but genetic components are involved in the etiology [10]. How ITGA8 would contribute to the pathological events of PD, is yet to be elucidated. There are reports of ITGA 8 being involved in neurological processes; a missense mutation in ITGA8 has been associated with schizophrenia in a Japanese cohort [11]. Further, ITGA8 is expressed in neuronal cells during development, where it regulates the outgrowth of neurites of sensory and motor neurons $[12,13]$. Mice lacking ITGA8 specifically in the forebrain have impaired long term potentiation. Although these mice do not present overt behavioral differences in learning and memory, ITGA 8 might be involved in memory function [14]. Nevertheless, ITGA8 is particularly important in kidney genesis; ITGA8 knock-out mice have severe kidney malformation and individuals with ITGA8 mutations develop bilateral renal agenesis [15, 16]. Another important candidate gene for PD, LRRK2 (Leucine-rich repeat kinase 2) also causes kidney alterations in rodents [17]. Apart from this similarity, there is no known functional connection between ITGA8 and PD.

The single nucleotide polymorphism (SNP) rs7077361 in ITGA8 was identified as a potential protective-factor for PD by Lill et al. [6]. This finding has subsequently been confirmed by Wang et al. who used a likelihood-based statistical approach that accounts for non-random nature of case-control samples in regard of genotypic distribution at the loci in populations under study and additionally confers flexibility to test for genetic association in presence of different confounding factors such as non-randomness of samples, population structure, etc. [18]. Rs7077361 (T vs. C, contig position 15509544, assembly GRCh38.p2) is an intronic SNP in ITGA8 (intron 28-29) and it has been linked to an expression quantitative trait loci (eQTL) in brain tissue in the caudate of the basal ganglia using the GTExPortal (http://www.gtexportal.org/home/). The purpose of this study was to investigate rs7077361 in an independent Swedish PD case-control material, to shed further light on the possible involvement of ITGA8 in PD.

\section{MATERIAL AND METHODS}

Blood samples from PD patients and controls were obtained from Karolinska University Hospital, Stockholm and from Sahlgrenska University Hospital in Gothenburg. DNA was obtained from blood samples according to standard protocols. PD patients were unrelated of Swedish descent and fulfilling the UK Brain Bank Clinical Diagnostic Criteria, with the exception that patients having one or more first, second, or third-degree relative diagnosed with PD were included [9]. Four individuals (three patients and one control individual) carrying the known pathogenic mutation G2019S in LRRK2 were excluded from the genetic analysis. As controls we included spouses of PD patients and individuals without neurological disease visiting the neurology-clinic $(=219)$, blood donors ( $\mathrm{n}=95$ ), and individuals from the SNAC-K (Swedish National Study on Aging and Care in Kungsholmen) project ( $\mathrm{n}=285$ ) (http://www.snac-k.se). Further specifications on the case-control material can be found in Table 1.

Table 1. Demographic characterization of case and controls.

\begin{tabular}{|c|c|c|c|c|c|}
\hline & Number of participants (n) & Females (\%) & Age (years) & Age of Onset (years) & Familial history of PD (\%) \\
\hline Control & 599 & 57.9 & 72.8 & N/A & N/A \\
\hline PD & 502 & 40.2 & 67.6 & 59.4 & 31.8 \\
\hline
\end{tabular}

$\mathrm{PD}=$ Parkinson's disease, Age of onset was defined as the age when the patient received a diagnosis, familial history was self-reported by interview, $\mathrm{n}=$ number of individuals.

Genotyping of rs7077361 was performed with TaqMan quantitative Real-time Polymerase Chain Reaction (PCR). We used a pre-made TaqMan SNP genotyping assay (C_25943434_20) and TaqMan Genotyping Mastermix (Thermo Fisher Scientific, Life Technologies Europe BV, Stockholm, Sweden). The ABI 7500 Fast cycler (Applied Biosystems, Foster City, CA, USA) was programmed as follows: pre-PCR read and activation, $60{ }^{\circ} \mathrm{C}$ for 1 minute and $95{ }^{\circ} \mathrm{C}$ for 10 minutes, followed by 50 cycles of $95^{\circ} \mathrm{C}$ for 15 seconds and $60{ }^{\circ} \mathrm{C}$ for 1 minute, and last post-PCR read at $60{ }^{\circ} \mathrm{C}$ for 1 minute. Genotypes TT, TC or CC were determined using the software provided with the instrument, 7500 Software v2.0.6 (Applied Biosystems). We achieved a call rate of $97 \%$. 
Power calculations were made using the PS Power and Sample size calculator, v.3 [19, 20]. With our sample size and an estimated minor allele frequency of 0.14 in individuals with European descent (http://www.ncbi.nlm.nih.gov/SNP), we have $80 \%$ power to detect an association with $0.579<$ OR $>1.572$.

Hardy-Weinberg equilibrium (HWE) was tested using the Online Encyclopedia for Genetic Epidemiology HWE tool (OEGE) [21]. Genotype and allele association were analyzed with Chi-squared $\left(\mathrm{X}^{2}\right)$ test and Fisher's exact test using GraphPad Prism 5.04 (GraphPad Software, Inc. La Jolla, CA, USA).

\section{RESULTS}

We have genotyped one SNP in the ITGA8 gene and tested for association with PD in a Swedish case-control material consisting of 502 PD patients and 599 controls. Our case-control material consists of a typical idiopathic Parkinson patient group; with an average age of onset of 60 years of age, slightly more men than women and around $30 \%$ of the patients report they have close relatives affected by the disorder (for details see Table 1). Genotyping was made with TaqMan quantitative Real-Time PCR with a call rate of 97\%. The study population was in HWE for rs7077361 with a $\mathrm{X}^{2}$ of 0.29 , as estimated using a $\mathrm{X}^{2}$ HWE calculator [21]. Genotype and allele frequencies are presented in Table 2. We found that the distribution of genotypes and alleles was highly similar in the patient and control groups. Statistical testing with $\mathrm{X}^{2}$ and Fisher's exact test was used to asses genotype and allele association respectively, gave non-significant $\mathrm{p}$-values $\left(\mathrm{p}\right.$-value $\mathrm{X}^{2}=0.67$, $\mathrm{p}$-value Fisher's exact test $\left.=0.82\right)$ and an odds ratio $(\mathrm{OR})$ of 0.96 (95\% confidence interval: 0.74-1.25) (Table 2).

Table 2. Results from the genotype and allele analysis for rs7077361.

\begin{tabular}{|c|c|c|c|c|c|}
\hline rs7077361 & C \% (n) & PD \% (n) & $X^{2}(d f)$ & OR (95\% CI) & p-value \\
\hline TT & $77.2(446)$ & $77.4(382)$ & \multirow{3}{*}{$0.800(2)$} & & \multirow{3}{*}{0.67} \\
\hline $\mathrm{TC}$ & $21.4(124)$ & $19.7(96)$ & & & \\
\hline $\mathrm{CC}$ & $1.4(8)$ & $1.9(9)$ & & & \\
\hline $\mathrm{T}$ & $87.9(1016)$ & $88.3(860)$ & \multirow{2}{*}{$0.049(1)$} & \multirow{2}{*}{$0.96(0.74-1.25)$} & \multirow{2}{*}{0.82} \\
\hline $\mathrm{C}$ & $12.1(140)$ & 11.7 (114) & & & \\
\hline
\end{tabular}

$\mathrm{C}=$ Control subjects, $\mathrm{PD}=$ Parkinson's disease, $\mathrm{n}=$ number of individuals, $\mathrm{X}^{2}=$ Chi-square, $\mathrm{df}=$ degrees of freedom, $\mathrm{OR}=\mathrm{Odds}$ ratio, $95 \% \mathrm{CI}=95 \%$ Confidence interval.

\section{DISCUSSION}

We have screened and analyzed the ITGA8 SNP rs7077361 in a Swedish PD case-control material, and we found no association between this marker and PD. The allele and genotype frequencies reported herein corresponds to the frequencies observed in individuals of European descent in publically available databases (http://www.ncbi.nlm.nih.gov/projects/SNP). Our results do not support the hypothesis of ITGA8 being involved in the etiology for PD. There can be several explanations for the discrepancy between our results and those published by Lill et al. For example, the studied populations have different genetic background from our Swedish case control material [6]. Whereas the rs7077361 variant presents a decreased risk for PD in the Caucasian populations included in the metaanalysis by Lill et al., it might not be linked to PD in the Swedish population. Also, rs7077361 is a noncoding SNP located in the $-29^{\text {th }}$ intron, there are no reports of rs7077361 being involved in or associated to other pathologies, nor is it known to affect splicing, conformation and stability of the transcript. Therefore it is possible that rs7077361 does not constitute the actual protective factor for PD, but reflects a linkage to another true disease-associated SNP. Another option is that we lack power to detect an association of feeble impact; as shown by our power analysis, we only have power to find an association with an OR smaller than 0.6 or higher than 1.6 while the OR reported by Lill et al. was 0.88 [6]. However it is important to consider that the discovery study consists of a meta-analysis, partly based on GWAS data and that such associations always need to be verified in independent well characterized populations.

\section{CONCLUSION}

This is the first report on genetic variants in ITGA8 and PD in Swedish PD today, in contrast to previous reports our findings do not support an association between rs7077361 and PD. More genetic studies in independent populations are warranted in order to conclude on the implication of ITGA8 in PD.

\section{CONFLICT OF INTEREST}

The authors confirm that this article content has no conflict of interest. 


\section{ACKNOWLEDGEMENTS}

We thank Professor Laura Fratiglioni for providing SNAC-K control samples and Daniel Bismut for technical assistance. This study was supported by The Swedish Research Council, The Swedish Parkinson Foundation, The Swedish Brain Foundation, Swedish Brain Power, Åke Wibergs stiftelse and Karolinska Institutet Funds.

\section{REFERENCES}

[1] Ekwa-Ekoka C, Diaz GA, Carlson C, et al. Genomic organization and sequence variation of the human integrin subunit alpha8 gene (ITGA8). Matrix Biol 2004; 23(7): 487-96.

[http://dx.doi.org/10.1016/j.matbio.2004.08.005] [PMID: 15579315]

[2] Schnapp LM, Breuss JM, Ramos DM, Sheppard D, Pytela R. Sequence and tissue distribution of the human integrin alpha 8 subunit: a beta 1associated alpha subunit expressed in smooth muscle cells. J Cell Sci 1995; 108(Pt 2): 537-44. [PMID: 7768999]

[3] Müller U, Bossy B, Venstrom K, Reichardt LF. Integrin alpha 8 beta 1 promotes attachment, cell spreading, and neurite outgrowth on fibronectin. Mol Biol Cell 1995; 6(4): 433-48. [http://dx.doi.org/10.1091/mbc.6.4.433] [PMID: 7626807]

[4] Zargham R, Thibault G. Alpha 8 integrin expression is required for maintenance of the smooth muscle cell differentiated phenotype. Cardiovasc Res 2006; 71(1): 170-8. [http://dx.doi.org/http://dx.doi.org/10.1016/j.cardiores.2006.03.003] [PMID: 16603140]

[5] Benoit YD, Lussier C, Ducharme PA, et al. Integrin alpha8beta1 regulates adhesion, migration and proliferation of human intestinal crypt cells via a predominant RhoA/ROCK-dependent mechanism. Biol Cell 2009; 101(12): 695-708. [http://dx.doi.org/10.1042/BC20090060] [PMID: 19527220]

[6] Lill CM, Roehr JT, McQueen MB, et al. Comprehensive research synopsis and systematic meta-analyses in Parkinson's disease genetics: The PDGene database. PLoS Genet 2012; 8(3): e1002548.

[http://dx.doi.org/10.1371/journal.pgen.1002548] [PMID: 22438815]

[7] Foo JN, Tan LC, Liany H, et al. Analysis of non-synonymous-coding variants of Parkinson's disease-related pathogenic and susceptibility genes in East Asian populations. Hum Mol Genet 2014; 23(14): 3891-7. [http://dx.doi.org/10.1093/hmg/ddu086] [PMID: 24565865]

[8] Parkinson J. An essay on the shaking palsy. 1817. J Neuropsychiatry Clin Neurosci 2002; 14(2): 223-36. [http://dx.doi.org/10.1176/jnp.14.2.223] [PMID: 11983801]

[9] Daniel SE, Lees AJ. Parkinson’s Disease Society Brain Bank, London: overview and research. J Neural Transm Suppl 1993; 39: 165-72. [PMID: 8360656]

[10] Ran C, Belin AC. The genetics of Parkinson's disease: review of current and emerging candidates. Journal of Parkinsonism and Restless Legs Syndrome 2014; 2014(4): 63-75. [http://dx.doi.org/http://dx.doi.org/10.2147/JPRLS.S38954]

[11] Supriyanto I, Watanabe Y, Mouri K, et al. A missense mutation in the ITGA8 gene, a cell adhesion molecule gene, is associated with schizophrenia in Japanese female patients. Prog Neuropsychopharmacol Biol Psychiatry 2013; 40: 347-52. [http://dx.doi.org/10.1016/j.pnpbp.2012.11.002] [PMID: 23153507]

[12] Varnum-Finney B, Venstrom K, Muller U, et al. The integrin receptor alpha 8 beta 1 mediates interactions of embryonic chick motor and sensory neurons with tenascin-C. Neuron 1995; 14(6): 1213-22. [http://dx.doi.org/10.1016/0896-6273(95)90268-6] [PMID: 7541634]

[13] Bossy B, Bossy-Wetzel E, Reichardt LF. Characterization of the integrin alpha 8 subunit: a new integrin beta 1-associated subunit, which is prominently expressed on axons and on cells in contact with basal laminae in chick embryos. EMBO J 1991; 10(9): $2375-85$. [PMID: 1714374]

[14] Chan CS, Chen H, Bradley A, Dragatsis I, Rosenmund C, Davis RL. alpha8-integrins are required for hippocampal long-term potentiation but not for hippocampal-dependent learning. Genes Brain Behav 2010; 9(4): 402-10. [http://dx.doi.org/http://dx.doi.org/10.1111/j.1601-183X.2010.00569.x.] [PMID: 20132319]

[15] Humbert C, Silbermann F, Morar B, et al. Integrin alpha 8 recessive mutations are responsible for bilateral renal agenesis in humans. Am J Hum Genet 2014; 94(2): 288-944. [http://dx.doi.org/10.1016/j.ajhg.2013.12.017]

[16] Muller U, Wang D, Denda S, Meneses JJ, Pedersen RA, Reichardt LF. Integrin alpha8beta1 is critically important for epithelial-mesenchymal interactions during kidney morphogenesis. Cell 1997; 88(5): 603-13. [http://dx.doi.org/http://dx.doi.org/10.1016/S0092-8674(00)81903-0] [PMID: 9054500]

[17] Ness D, Ren Z, Gardai S, et al. Leucine-rich repeat kinase 2 (LRRK2)-deficient rats exhibit renal tubule injury and perturbations in metabolic and immunological homeostasis. PLoS One 2013; 8(6): e66164. [http://dx.doi.org/10.1371/journal.pone.0066164] [PMID: 23799078]

[18] Wang M, Wang L, Jiang N, Jia T, Luo Z. A robust and efficient statistical method for genetic association studies using case and control samples from multiple cohorts. BMC Genomics 2013; 14: 88. 
[http://dx.doi.org/10.1186/1471-2164-14-88] [PMID: 23394771]

[19] Dupont WD, Plummer WD Jr. Power and sample size calculations. A review and computer program. Control Clin Trials 1990; 11(2): 116-28. [http://dx.doi.org/10.1016/0197-2456(90)90005-M] [PMID: 2161310]

[20] Dupont WD, Plummer WD Jr. Power and sample size calculations for studies involving linear regression. Control Clin Trials 1998; 19(6): $589-601$.

[http://dx.doi.org/10.1016/S0197-2456(98)00037-3] [PMID: 9875838]

[21] Rodriguez S, Gaunt TR, Day IN. Hardy-Weinberg equilibrium testing of biological ascertainment for Mendelian randomization studies Am J Epidemiol 2009; 169(4): 505-14.

[http://dx.doi.org/http://dx.doi.org/10.1093/aje/kwn359] [PMID: 19126586]

(C) Ran et al.; Licensee Bentham Open.

This is an open access article licensed under the terms of the Creative Commons Attribution-Non-Commercial 4.0 International Public License (CC BY-NC 4.0) (https://creativecommons.org/licenses/by-nc/4.0/legalcode), which permits unrestricted, non-commercial use, distribution and reproduction in any medium, provided the work is properly cited. 